\title{
Load-Displacement Behavior of Sacroiliac Joints
}

\author{
J. A. A. Miller, A. B. Schultz, and *G. B. J. Andersson \\ Biomechanics Research Laboratories, Department of Mechanical Engineering and Applied Mechanics, \\ University of Michigan, Ann Arbor, Michigan, U.S.A.; and *Department of Orthopedic Surgery-I, Sahlgren Hospital, \\ University of Göteborg, Göteborg, Sweden
}

\begin{abstract}
Summary: We measured the load-displacement behavior of both single and paired sacroiliac (SI) joints in fresh cadaver specimens obtained from eight adults between the ages of 59 and 74 years. With both ilia fixed, static test loads were applied to the center of the sacrum along and about axes parallel and normal to the superior S1 endplate. Test forces up to $294 \mathrm{~N}$ were applied in the superior, inferior, anterior, posterior, and lateral directions. Moments up to $42 \mathrm{~N}$-m were applied in flexion, extension, lateral bending, and axial torsion. Displacements of the center of the sacrum were measured $60 \mathrm{~s}$ after each load increment was applied, using dial gauges and an optical lever system. The tests were then repeated with only one ilium fixed. Finally, the three-dimensional location and overall geometry of each SI joint were measured. For an isolated left joint at the maximum test loads, the mean (SD) sacral displacements in the direction of the force ranged from $0.76 \mathrm{~mm}(1.41)$ in the medial to $2.74 \mathrm{~mm}$ (1.07) in the anterior direction. The mean rotations in the directions of the moments ranged from $1.40^{\circ}(0.71)$ in right lateral bending to $6.21^{\circ}(3.29)$ in clockwise axial torsion viewed from above. We also examined load-displacement behavior under larger loads. Single sacroiliac joints resisted loads from 500 to $1440 \mathrm{~N}$, and from 42 to $160 \mathrm{~N}-\mathrm{m}$ without overt failure. Key Words: Pelvis-Sacroiliac joint-Sacral geometry - Spine biomechanics.
\end{abstract}

The sacroiliac (SI) joints have long been suspected as a possible site of at least some low back disorders [for reviews see, for example, Grieve (15) and Bellamy et al. (2)]. The anatomy and histology of the SI joints have been the subject of many studies $(1,6,7,17,22,25,27,28,30,32-35)$. In addition, radiographic $(5,8,10,11,23)$ and kinematic $(9,12,13,24)$ studies have sought to define normal and abnormal ranges of motion in these articulations. There are at least two studies in which the loads carried by these joints have been estimated using theoretical models $(14,20)$, but only a few studies have been made of the mechanical properties of these articulations $(4,16,29,31)$.

Address correspondence and reprint requests to J. A. A. Miller at Department of Mechanical Engineering and Applied Mechanics, University of Michigan, Ann Arbor, MI 48109-2125, U.S.A.
Because of their location, SI joints must resist large loads during daily activities. Studies of joint motions in response to these loads, as well as analyses of the stresses and strains to which the substructures of these joints are subjected, all require knowledge of mechanical properties of these complex synovial and fibrotic articulations. As no comprehensive data seemed to have been published on the mechanical properties of isolated fresh SI joints, we undertook this study of SI joint load-displacement behavior.

\section{METHODS}

Eight fresh bilateral SI joint specimens were obtained at autopsy within $12 \mathrm{~h}$ after death from seven males and one female aged between 59 and 74 years (mean, 66 years). Computer tomography scans of each specimen were obtained to check for radio- 
graphic abnormalities. One joint was found to be ankylosed unilaterally and this was excluded from the study. No other abnormalities were found. Each ilium was sectioned approximately $10 \mathrm{~cm}$ lateral to the SI joint and, together with the sacrum and the overlying soft tissues, was removed and preserved at $-20^{\circ} \mathrm{C}$ until just before testing. During mounting and testing, specimens were kept moist at room temperature.

Specimens were freed of all muscular tissue, and the sacral spinous processes were removed. Each ilium lateral to the SI joint line was stripped of its periosteum. Each ilium was cast into a block of acrylic cement after some 20 screws were partially inserted and distributed over its surface to improve fixation. Care was taken not to include the anterior or posterior SI ligament complex. The iliac blocks were then bolted rigidly to the test apparatus with the first sacral endplate horizontal (Fig. 1). Steel plates were mounted on the anterior and posterior surfaces of the sacrum using four steel wires and a central bolt. More cement was placed between the plates and the sacral surfaces to improve congruency of mating surfaces. The bolts and wires were then tightened. A loading arm was attached normal to each plate. Cables were attached to these arms such that static test forces and moments could be applied in three orthogonal directions through the center of the sacrum (point $O$, Fig. 1) via pulleys and weights.

The center of the superior sacral endplate was defined as lying halfway along the maximum diam-
$1 \mathrm{~A}$

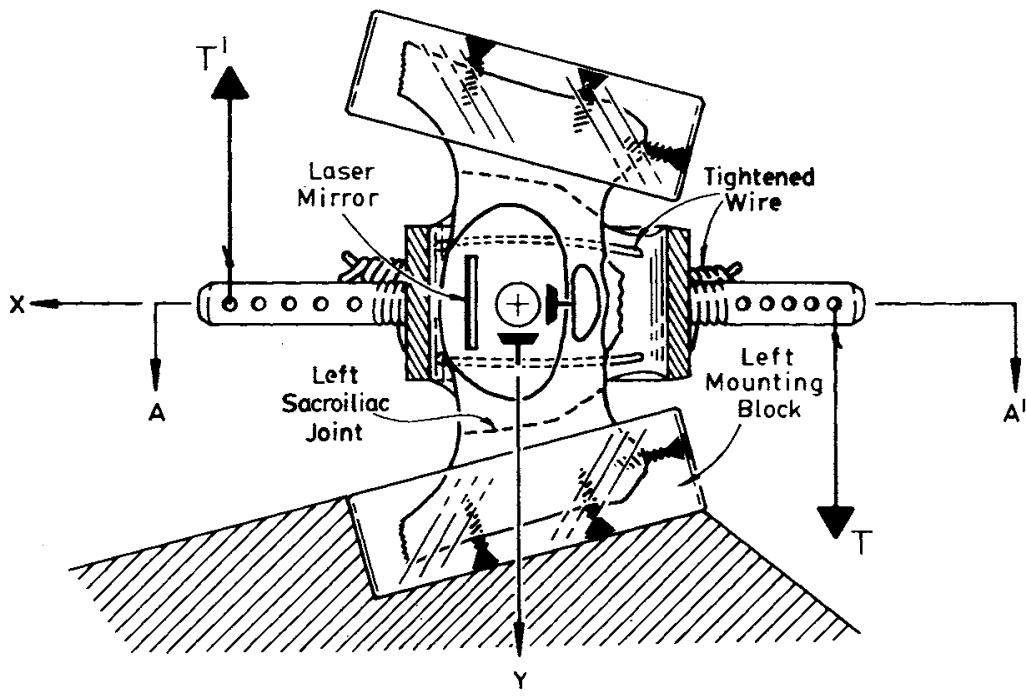

$1 B$

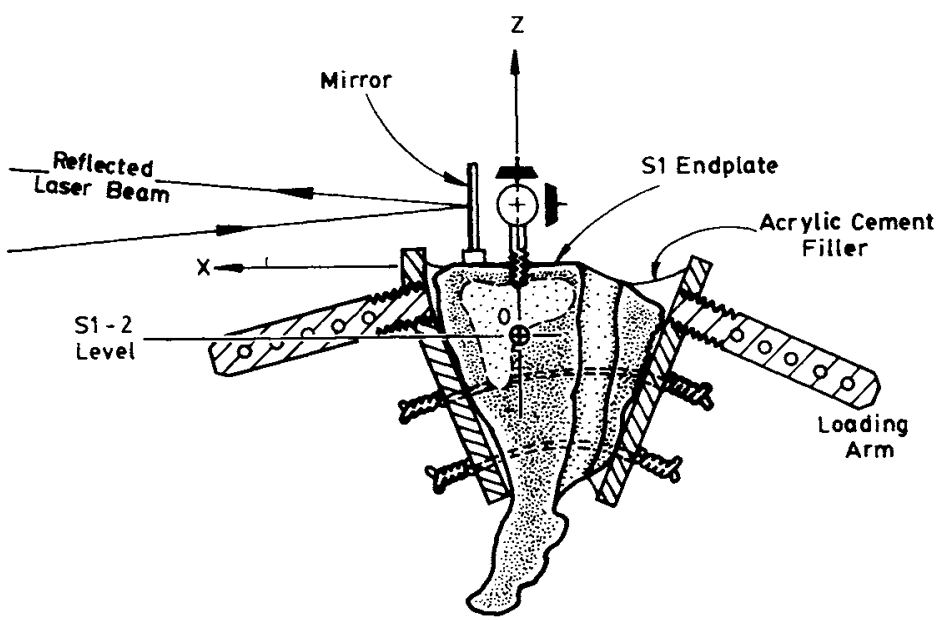

FIG. 1. Specimen mounting for load-displacement tests of left sacroiliac joint. In a clockwise torsion test (A) a couple, $\mathrm{TT}^{\prime}$, was applied about the center of the sacrum (point $O$ ) via loading arms and steel plates fastened to the sacrum with tightened steel wires. Three othogonally-placed dial gauges were used to measure translations of the ball, while a mirror and optical lever system allowed measurement of sacral rotations about two axes. Section $A^{\prime} A^{\prime}$ (B) shows a midsagittal plane section through the mounted specimen. The vertical adjustment for each loading arm is not shown.

SECTION A- $A^{\prime}$ 
TABLE 1. Summary of main ( $m$ ) and coupled (c) sacral displacements calculated for the center $(O)$ of the sacrum in each test direction (The remaining displacements were assumed to be negligible)

\begin{tabular}{|c|c|c|c|c|c|c|}
\hline \multirow{2}{*}{$\begin{array}{c}\text { Test } \\
\text { direction }\end{array}$} & \multicolumn{3}{|c|}{ Translation of $\mathrm{O}$} & \multicolumn{3}{|c|}{ Rotations of $O$} \\
\hline & $X$ & $Y$ & $Z$ & $\theta_{x}$ & $\theta_{\mathrm{y}}$ & $\theta_{z}$ \\
\hline$F_{\mathrm{x}}$ & $\mathrm{m}$ & $\mathrm{c}$ & $\mathrm{c}$ & - & $c$ & $\mathrm{c}$ \\
\hline$F_{\mathrm{y}}$ & c & $\mathrm{m}$ & $\mathrm{c}$ & - & $\mathfrak{c}$ & c \\
\hline$F_{z}$ & $c$ & $c$ & $\mathrm{~m}$ & c & c & - \\
\hline$M_{\mathrm{x}}$ & $c$ & $\mathrm{c}$ & $\mathrm{c}$ & $\mathrm{m}$ & $\mathrm{c}$ & - \\
\hline$M_{\mathrm{y}}$ & $\mathrm{c}$ & $\mathrm{c}$ & $\mathrm{c}$ & $c$ & $\mathrm{~m}$ & - \\
\hline$M_{\mathrm{z}}$ & $\mathrm{c}$ & $\mathrm{c}$ & $\mathrm{c}$ & - & $\mathrm{c}$ & $\mathrm{m}$ \\
\hline
\end{tabular}

eter of the endplate in the midsagittal and frontal planes.

The center of the sacrum was defined as lying in the midsagittal plane, midway between the inferior S1 and superior S2 vertebral endplates and the anterior and posterior margins of the auricular SI joint surfaces viewed laterally. The mean value of the center of the sacrum was $29.0 \mathrm{~mm}$ inferior and 11.5 $\mathrm{mm}$ posterior to the center of the superior S1 endplate as confirmed by specimen dissection and sectioning after testing was completed.

\section{Measurement of Load-Displacement Response}

The three orthogonal displacements of a $25 \mathrm{~mm}$ diameter ball, mounted rigidly $60 \mathrm{~mm}$ over the center of the sacral endplate, were measured using three orthogonally-placed dial gauges (Fig. 1), each with a resolution of $0.05 \mathrm{~mm}$. Sacral rotations about two axes were measured using an optical lever. A laser beam was reflected from a mirror mounted rigidly to the sacrum onto a wall $5 \mathrm{~m}$ away. Measurements of the vertical and horizontal displacements of the reflected beam provided angular resolution of $\pm 0.01^{\circ}$. From these data and knowledge of specimen geometry, the main displacement and four coupled displacements (Table 1) of the center $(\mathrm{O})$ of the sacrum were calculated using rigid body kinematic theory. The results from a pilot study suggested the remaining displacements were negligible.

Initially, both ilia were rigidly fixed to the test stand and forces of 39,118 , or $294 \mathrm{~N}$ and moments of 6,17 , or $42 \mathrm{~N}$-m were applied. These loads were applied in the following order: anterior, posterior, flexion, extension, superior, inferior, axial torsion,

TABLE 2. Overview of specimen geometry (sacral component only)

\begin{tabular}{|c|c|c|c|c|c|}
\hline \multicolumn{2}{|l|}{ Dimension } & Mean $(\mathrm{SD})$ & Range & & \\
\hline \multicolumn{6}{|l|}{ Superior S1 endplate } \\
\hline AP dia. & & $35.8(6.0)$ & $25.2-42.6$ & & \\
\hline Lat. dia. & & $60.3(4.9)$ & $52.8-66.1$ & & \\
\hline Area & & $1704(370)$ & $1050-2090$ & & \\
\hline \multicolumn{6}{|l|}{ SI Joint auricular surface } \\
\hline Height & $a$ & $63.4(3.8)$ & $57.9-68.8$ & & \\
\hline Width & $b$ & $38.7(3.2)$ & $33.4-43.3$ & & \\
\hline Frontal $(Y Z)$ plane angle & $\psi$ & $19.6(10.8)$ & $6.5-32.5$ & & \\
\hline Joint area & & $1424(203)$ & $1104-1913$ & & \\
\hline Ligamentous area & & $2229(429)$ & $1815-3200$ & & \\
\hline \multirow[t]{4}{*}{ Centroid coords. } & $C_{x}$ & $-8.9(10.5)$ & $-30.2-3.8$ & & \\
\hline & $\mathrm{C}_{\mathrm{z}}$ & $-30.9(7.4)$ & $-15.4--44.1$ & & \\
\hline & & \multicolumn{2}{|c|}{ S1-S2 section $\left(A^{\prime}\right)$} & \multicolumn{2}{|c|}{$\mathrm{S} 2-\mathrm{S} 3$ section } \\
\hline & & Mean $(\mathrm{SD})$ & Range & Mean (SD) & Range \\
\hline \multicolumn{6}{|l|}{ SI Joint proper } \\
\hline Jt. width & $b_{1}$ & $24.6(4.3)$ & $19.1-34.5$ & $18.5(4.5)$ & $10.6-26.2$ \\
\hline Jt. spacing & $c_{1}$ & $107.8(9.6)$ & $97.2-120.9$ & $97.9(6.4)$ & $88.3-108.0$ \\
\hline Transverse $(X Y)$ plane angle & $\theta_{1}$ & $1.6(8.8)$ & $-7.0-17.0$ & $-4.9(13.0)$ & $-32.0-12.0$ \\
\hline Midpoint coords. & $A_{x}$ & $-11.5(9.4)$ & $-28.8-2.1$ & $-4.6(13.8)$ & $-31.2-13.3$ \\
\hline & $A_{z}$ & $-29.0(4.1)$ & $-21.9--36.7$ & $-56.5(3.5)$ & $-49.0--62.2$ \\
\hline \multicolumn{6}{|l|}{$\begin{array}{l}\text { Posterior ligamentous } \\
\text { attachment surface }\end{array}$} \\
\hline Width & $b_{2}$ & $30.7(4.2)$ & $24.1-38.0$ & $22.2(4.9)$ & $16.3-30.0$ \\
\hline Spacing & $c_{2}$ & $91.3(7.6)$ & $81.5-105.2$ & $81.1(7.7)$ & $70.2-92.3$ \\
\hline Transverse $(X Y)$ plane angle & $\theta_{2}$ & $-34.7(10.5)$ & $-83.0--40.0$ & $-45.5(7.0)$ & $-54.0--45.0$ \\
\hline Location, length & $\mathrm{AP}_{\mathrm{x}}$ & $24.3(2.5)$ & $21.8-28.1$ & $17.3(3.9)$ & $11.0-22.0$ \\
\hline
\end{tabular}

Left and right sided results have been pooled. Values are in millimeters or degrees; areas are in square millimeters. Dimension symbols are defined in text and shown in Fig. 2.

AP dia., anteroposterior diameter; Lat. dia., lateral diameter; SI, sacroiliac. 
lateral bending, and medial. Test loads were oriented parallel to the axes shown in Fig. 1. Anterior and posterior shear loads were applied parallel to the superior $\mathrm{S} 1$ endplate using a single cable and weight. Two cables and two equal weights were used to apply the remaining test loads. Superior and inferior shear forces were applied normal to the superior S1 endplate and the lateral test force was applied parallel to the superior S1 endplate. Two cables and two equal weights were used to apply moments in extension, lateral bending, and torsion clockwise (CW) about the longitudinal $(z)$ axis of the sacrum. One ilium was then released from the test stand, and the full test sequence repeated.

Motions in the different test directions were compared at loads of $294 \mathrm{~N}$ or $42 \mathrm{~N}-\mathrm{m}$. The stiffness in a given test direction was defined as the test load in that direction divided by the displacement of the center of the sacrum or the sacral rotation in the same direction. In matrix representation this definition of stiffness is equivalent to the inverse of the flexibility coefficient, a value not equal to the stiffness coefficient (21).

For failure testing, eight single SI joints were tested in one of the eight test directions, increasing the load in $50 \mathrm{~N}$ or $5 \mathrm{~N}-\mathrm{m}$ increments until either failure occurred or a limit of $1440 \mathrm{~N}$ or $160 \mathrm{~N}$-m was reached.

\section{Measurement of Sacral Geometry}

The geometry of the SI joints was determined by measurements made on their projected images (scaled $\times 2$ ). Photographs included frontal and lateral views of the specimen parallel to the superior S1 endplate, and views taken normal to each joint surface. Similarly, photographs were also taken of transverse $(X Y)$ plane sections made through the specimen midway between the inferior $\mathrm{S} 1$ and superior S2 endplates (termed S1-2 section) and between the inferior $\mathbf{S} 2$ and superior S3 endplates (termed S2-3 section). Where landmarks were indistinct, black ink was used to outline or mark them to ensure visibility in the photographs.

Linear measurements were made using dial calipers $(0.05 \mathrm{~mm})$ and corrected for magnification using a scale placed adjacent to the specimen in the same plane as the parameter to be measured. Dimensions were defined relative to the origin of the orthogonal coordinate system at the center of the superior S1 endplate (Fig. 2).
Angles were measured to the nearest degree measured using a protractor. The inclination of the joint surface to the sagittal plane in the transverse $(X Y)$ plane (angle $\theta$ ) was determined by drawing a double tangent to the auricular surface at the S1-2 level (Section $\mathrm{AA}^{\prime}$, Fig. 2). The midpoint of this double tangent was labeled as A. Similarly, for the area of ligamentous attachment posterior to the joint, a second double tangent with midpoint $\mathrm{P}$ was defined. The distance between points $A$ and $P$ in the anteroposterior $(X)$ direction was found and defined as $\mathrm{AP}_{x}$. The inclination of the joint surface to the vertical was determined in the frontal $(Y Z)$ plane (angle $\psi$ ) passing through the midpoints (A) of the left and right joint surfaces. To measure joint areas and centroids a slide of the view normal to each joint surface was projected onto paper and the joint outline was traced on the paper. The joint shape was then cut out, weighed, and its balance point found. Joint areas and centroid locations
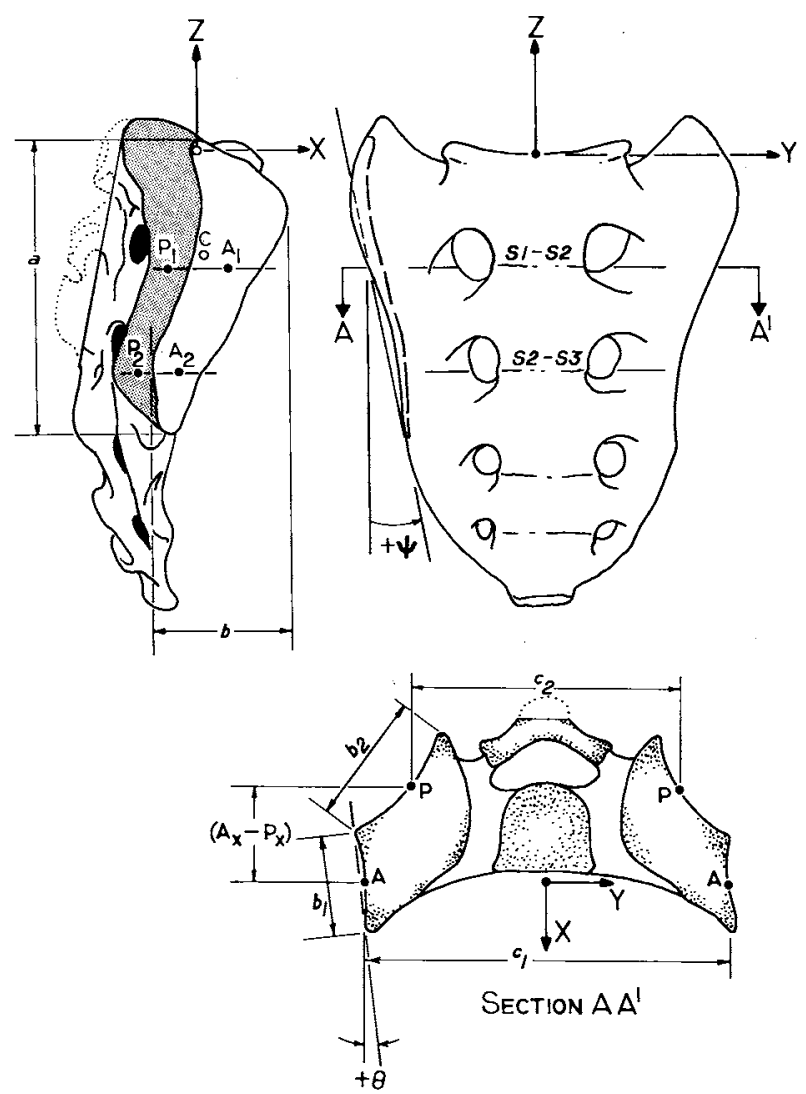

FIG. 2. Right (top left) and frontal views (top right) of a sacrum showing some of the geometric dimensions measured. Section AA is a top view of a section through the sacrum at the S1-S2 level. 
could thus be found knowing image magnification and paper density.

\section{Measurement Repeatability}

Linear measurements were made directly on the specimens using dial calipers with a resolution of $0.01 \mathrm{~mm}$. The largest source of error in such measurements was variability in the definition of the relevant landmarks. To estimate measurement repeatability we repeated measurement of auricular joint height (dimension $a$, Table 2 ) in four joints on four different days. The standard error (SE) of the measurement was $0.33 \mathrm{~mm}$ or $0.55 \%$ of the mean value. Similarly, the SE of angular measure $\theta_{2}$ (Table 1, Fig. 2) was $0.7^{\circ}$ or $2.0 \%$ of the mean value, while the SE of the auricular joint area measurement was $18.7 \mathrm{~mm}^{2}$ or $1.31 \%$ of the mean value.

Finally, estimates were made of displacement measurement accuracies. Single SI joint extension tests were repeated in three specimens. The SE of the main rotation of point $\mathrm{O}$ was found to be $0.11^{\circ}$ or $3.1 \%$ of the mean value at the $42 \mathrm{~N}$-m load level. Similarly, the SE of the $X$ (or posterior) translation measurement was found to be $0.23 \mathrm{~mm}$ or $38.3 \%$ of the mean value. These values include the effects of tissue hysteresis in addition to errors arising due to the measurement method itself.

\section{RESULTS}

\section{Specimen Geometry}

The parameters describing the geometry of the sacrum and sacral surfaces of the SI joints are listed in Table 2. The area of each joint was about $84 \%$ of that of the superior S1 endplate, and joint dimensions were roughly similar to those of the superior S1 endplate. At the S1-2 level the SI joints were oriented in an anteroposterior direction, wedged approximately $20^{\circ}$ to the vertical, and spaced approximately $108 \mathrm{~mm}$ apart. The average distance of the centroid of the auricular SI joint surface (point C, Fig. 2) was $1.9 \mathrm{~mm}$ inferior and $2.6 \mathrm{~mm}$ anterior to the center of the sacrum, as defined in this study. Thus, test forces and moments were applied through the point $O$ (in the midsagittal plane), which lay within an average distance of $3 \mathrm{~mm}$ of a line joining the left and right SI auricular joint surface centroids (point $\mathrm{C}$, Table 2).

The ligamentous attachment area was nearly $60 \%$ larger than the auricular joint surface lying further anteriorly, and angled from 35 to $45^{\circ}$ to that surface in the transverse plane (Table 2).

\section{Load-Displacement Response}

When a $294 \mathrm{~N}$ test load was applied with both ilia fixed, the smallest motions occurred in response to mediolateral forces, larger motions accompanied superior and inferior forces, and still larger motions resulted from anterior or posterior shear forces (Table 3). In the $42 \mathrm{~N}$-m moment tests, the smallest rotations occurred in lateral bending and the largest in extension.

When the specimens were gripped by the left ilium only, the main sacral translations in response to the same force level ( $294 \mathrm{~N})$ increased threefold or more. Again, the smallest translations occurred in the medial direction, while the largest translations occurred in the direction of the superior, anterior, and posterior test forces. In the corresponding moment tests at $42 \mathrm{~N}$-m, the isolated left SI joint was again stiffest in right lateral bending, but was now least stiff in torsion. In general, the average main rotations measured with one ilium fixed ranged from two times to 7.8 times the rotations measured when both ilia were fixed (Table 3 ).

Motions occurring in directions other than the direction of the test load are termed coupled motions (Table 1). Coupled motions occurred in every test direction except torsion where they were negligible (Table 4). In response to superior and inferior forces with only the left ilium fixed, for example, coupled rotations in lateral bending were substantial, but coupled translations were negligible. In this case, rotations probably occurred because of the large bending moment (16 N-m at $294 \mathrm{~N}$ load)

TABLE 3. Mean displacements $(\mathrm{mm})$ and rotations (degs) of the center of the sacrum in each test direction

\begin{tabular}{lllll}
\hline & & & \multicolumn{2}{c}{ One ilium fixed } \\
\cline { 4 - 5 } \multicolumn{2}{c}{ Test direction/load } & $\begin{array}{c}\text { Both ilia fixed } \\
\text { (mean) }\end{array}$ & Mean & Range \\
\hline Superior & $294 \mathrm{~N}$ & $0.28(0.25)^{a}$ & $1.87(1.76)^{a}$ & $0.20-5.75$ \\
Inferior & $294 \mathrm{~N}$ & $0.26(0.13)$ & $0.99(0.43)$ & $0.47-1.63$ \\
Anterior & $294 \mathrm{~N}$ & $0.48(0.38)$ & $2.74(1.07)$ & $0.02-2.90$ \\
Posterior & $294 \mathrm{~N}$ & $0.53(0.75)$ & $1.58(1.69)$ & $0.31-4.98$ \\
Medial & $294 \mathrm{~N}$ & $0.01(0.08)$ & $0.76(1.41)$ & $0.64-3.65$ \\
Flexion & $42 \mathrm{~N}-\mathrm{m}$ & $1.31(0.60)$ & $2.68(1.59)$ & $0.91-4.53$ \\
Extension & $42 \mathrm{~N}-\mathrm{m}$ & $1.94(1.29)$ & $3.52(1.46)$ & $1.92-4.66$ \\
Lateral bending & $42 \mathrm{~N}-\mathrm{m}$ & $0.37(0.27)$ & $1.40(0.71)$ & $0.41-2.16$ \\
Torsion & $42 \mathrm{~N}-\mathrm{m}$ & $0.80(0.51)$ & $6.21(3.29)$ & $1.15-8.25$ \\
\hline
\end{tabular}

${ }^{a}$ Standard deviations in parentheses. 
TABLE 4. Largest mean coupled displacements $(\mathrm{mm})$ and mean coupled rotations (degs) of the center $(O)$ of the sacrum under maximum test loads

\begin{tabular}{|c|c|c|c|c|c|c|}
\hline & & \multicolumn{2}{|c|}{ Both ilia fixed } & \multicolumn{3}{|c|}{ Left ilium fixed } \\
\hline \multicolumn{2}{|c|}{ Test direction and load } & Anterior & Flexion & Anterior & Flexion & \\
\hline Superior & $294 \mathrm{~N}$ & $0.06(0.27)$ & $-0.11(0.32)$ & $-0.01(0.55)$ & $0.27(0.41)$ & $-1.37(0.43)^{a}$ \\
\hline \multirow[t]{2}{*}{ Inferior } & $294 \mathrm{~N}$ & $0.02(0.19)$ & $0.13(0.23)$ & $-0.54(0.46)$ & $-0.16(0.20)$ & $0.85(0.34)^{a}$ \\
\hline & & Superior & Flexion & Superior & Flexion & \\
\hline Anterior & $294 \mathrm{~N}$ & $0.07(0.58)$ & $0.63(0.77)$ & $-0.18(0.68)$ & $0.51(1.21)$ & $2.73(1.50)^{b}$ \\
\hline Posterior & $294 \mathrm{~N}$ & $0.13(0.09)$ & $-0.25(0.19)$ & $0.23(0.42)$ & $-0.88(0.73)$ & $-2.56(1.98)^{b}$ \\
\hline \multirow[t]{2}{*}{ Right medial } & $294 N$ & $0.05(0.10)$ & $0.02(0.05)^{a}$ & $0.39(0.70)$ & $0.01(0.74)^{a}$ & \\
\hline & & Anterior & Superior & Anterior & Superior & \\
\hline Flexion & $42 \mathrm{~N}-\mathrm{m}$ & $0.14(0.59)$ & $-0.12(0.34)$ & $0.69(2.42)$ & $-0.34(0.52)$ & \\
\hline Extension & $42 \mathrm{~N}-\mathrm{m}$ & $0.42(2.08)$ & $-0.62(2.22)$ & $-0.60(2.60)$ & $1.39(0.92)$ & \\
\hline Right lateral bending & $42 \mathrm{~N}-\mathrm{m}$ & $-0.28(0.60)^{c}$ & $-0.13(0.25)$ & $-1.71(3.51)^{c}$ & $-0.76(0.40)$ & \\
\hline
\end{tabular}

Standard deviation in parentheses.

${ }^{a}$ Right lateral flexion (degrees); ${ }^{b}$ Counterclockwise rotation (degrees); ${ }^{c}$ Right (mm).

that arose due to the approximately $53 \mathrm{~mm}$ offset (Table 1) of the load from the left SI joint. Similarly, coupled torsional rotations of approximately $3^{\circ}$ occurred in anteroposterior shear tests. A mediallydirected test force tended to cause separation of the SI joint by pure translation. Lateral bending moments caused translations of the center of the sacrum averaging $1.7 \mathrm{~mm}$, while flexion and extension moments caused average upward translations of 0.3 and $1.4 \mathrm{~mm}$ in the inferior and superior directions, respectively (Table 4).

During the low-load testing sequence, four single joints failed in torsion and one failed in each of the posterior extension and lateral bending tests. In all four torsion tests, failure occurred in the ligaments on the anterior and superior aspects of the joint, which were placed primarily under tensile stress.

The large-load tests were conducted both to examine the linearity of the load-displacement results and to estimate failure load values. Fourteen tests were conducted on eight single SI joints. Load-displacement curves found in these tests were quite linear (Figs. 3 and 4), and thus values cited in Tables 3 and 4 should be reliable indicators of SI

FIG. 3. Force-translation curves from large load tests of four single sacroiliac joint specimens in the directions indicated. Note the linearity of the curves.

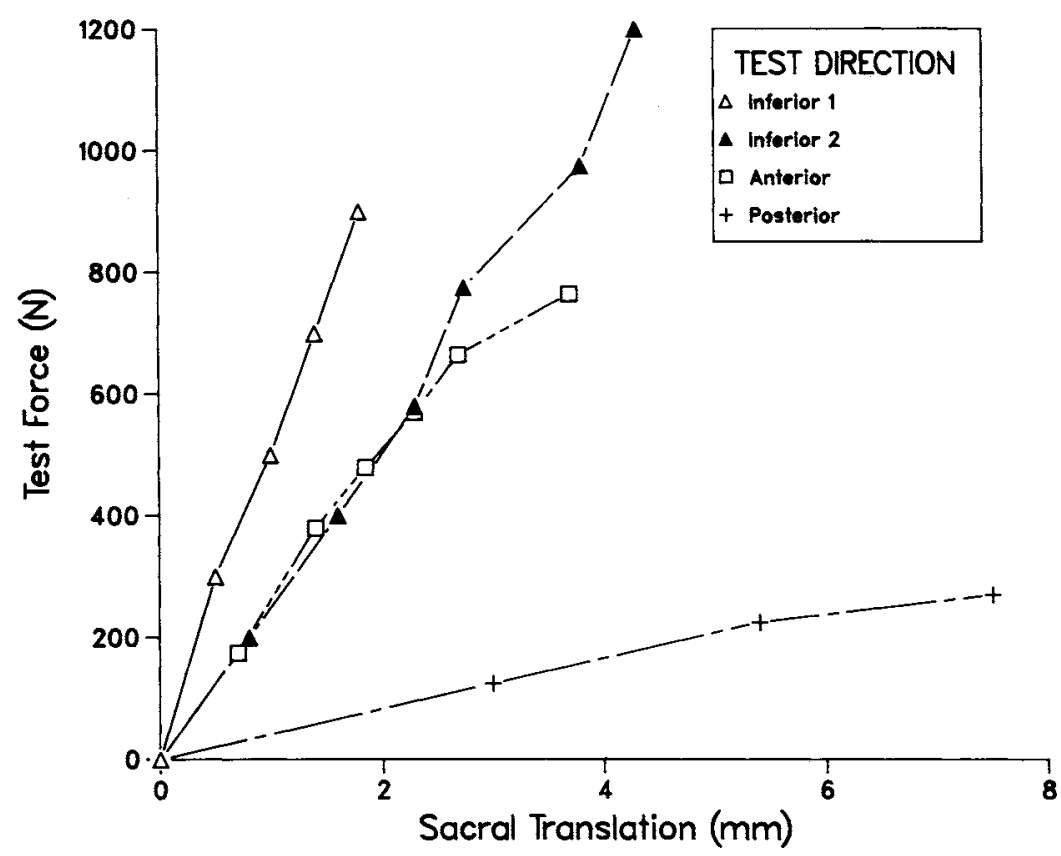




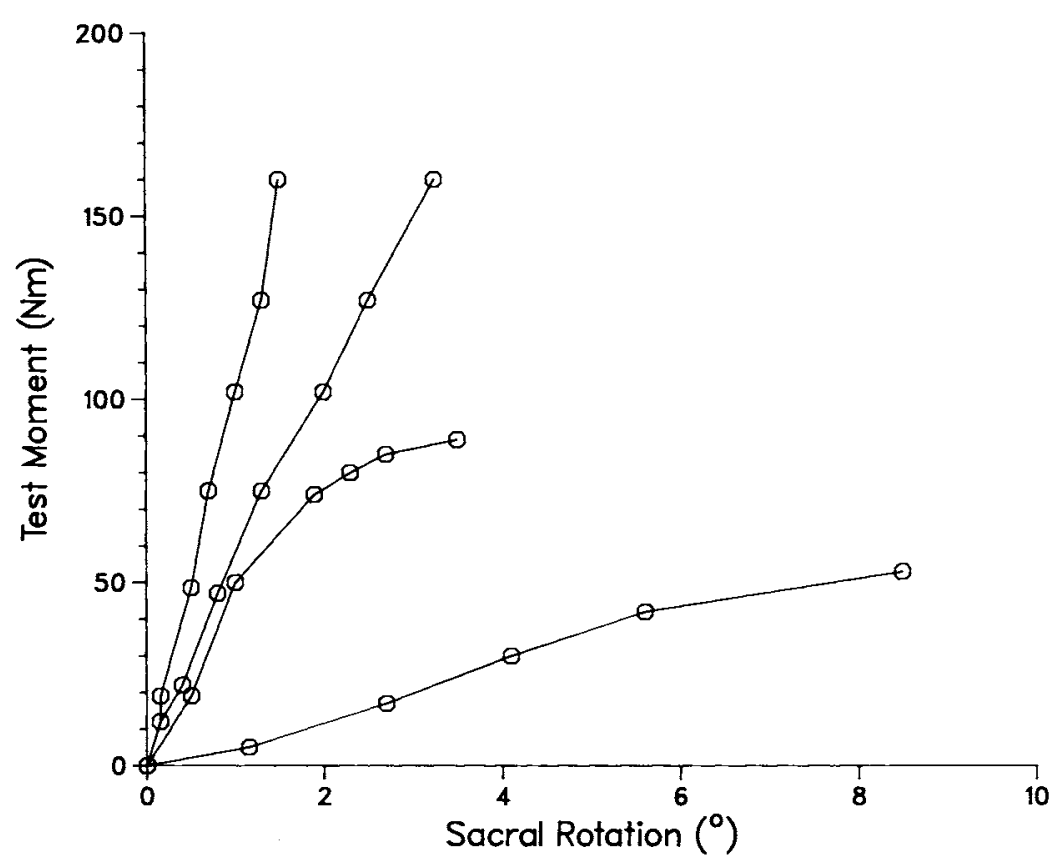

FIG. 4. Moment-rotation curves in flexion large-load tests of single sacroiliac joints. The two curves exceeding $150 \mathrm{~N}-\mathrm{m}$ are from the left and right sacroiliac joints of the same cadaver. joints stiffness at any load level up to failure. These tests showed that all eight specimens resisted loads up to $500 \mathrm{~N}$ or $50 \mathrm{~N}-\mathrm{m}$ without failure in the eight primary test directions. In a second test on each specimen, failure occurred below $30 \mathrm{~N}-\mathrm{m}$ in lateral bending ( $\mathrm{n}=1), 52 \mathrm{~N}-\mathrm{m}$ in torsion (1), from 50 to $100 \mathrm{~N}-\mathrm{m}$ in extension (2) and lateral bending (1), and at $500 \mathrm{~N}$ in posterior shear (1). Other specimens resisted loads without failure up to $160 \mathrm{~N}-\mathrm{m}$ in flexion (2), $1200 \mathrm{~N}$ in inferior (1), and $1440 \mathrm{~N}$ (1) in superior load tests. Apart from the torsion tests where failure was ligamentous, the failures occurred in the bone medial to the SI joint.

\section{DISCUSSION}

We tested SI joints in two different situations. When both ilia were fixed, motions in the two joints tended to be small. Displacements did not exceed $0.5 \mathrm{~mm}$ in response to the $294 \mathrm{~N}$ test forces, and rotations did not exceed $1.9^{\circ}$ in response to the 42 $\mathrm{N}$-m test moments (Table 3 ). The corresponding coupled displacements were also small (Table 4). Although it provides useful information this test situation probably does not represent the situation in vivo, as the fixation method precluded lateral separation of the ilia from the sacrum. This, combined with the characteristic surface irregularities of the SI joint surfaces themselves (33), probably yielded larger joint stiffness values than would have been expected had ilial separation been allowed. The small displacement in the mediolateral test direction primarily reflects the compression stiffness of the cartilagenous surfaces of the joint, which had an area of about $14 \mathrm{~cm}^{2}$.

With only the one ilium fixed, the ipsilateral SI joint is subjected to the full test load and sacral rotations are unconstrained. This type of test reflects loading conditions that can arise in one-legged stance in vivo. There, the ipsilateral SI joint and the symphysis pubis are the primary passive structures able to resist the lateral bending moment due to spine compression forces arising from upper body weight. In anteroposterior and superior-inferior tests, a test force actually applied a combined shear and bending load (about $16 \mathrm{~N}-\mathrm{m}$ at $294 \mathrm{~N}$ ). This resulted in significantly larger motions in single joint tests than when both ilia were fixed. On average, these increases were fivefold and threefold at the $294 \mathrm{~N}$ and $42 \mathrm{~N}$-m load levels, respectively (Table 3).

For the single SI joint tests, the largest translations occurred in anterior shear and the largest rotations occurred in torsion. The torsion moment was directed so as to place the anterior joint capsule in tension rather than stress the more extensive dorsal accessory ligaments (32). We would expect torsional stiffness in the opposite direction to be larger because of the extent of these dorsal ligaments. 
The geometric study of these complicated articulations gives overall linear, angular, and area data for these particular specimens. Its purpose was to provide geometric data suitable for input to mathematical models of the pelvic ring. We did not measure the surface topology of the auricular joints themselves, as this has already been described by Weisl (33).

The overall dimensions of these SI joints were 63 $\times 39 \mathrm{~mm}$ (Table 1 ), which compare favorably with those of Weisl $(58 \times 35 \mathrm{~mm})$ for a much larger adult population (33). The area of the auricular joint was found to be about $14 \mathrm{~cm}^{2}$ or somewhat less than the $18 \mathrm{~cm}^{2}$ figure cited by Sashin (26). As our methods showed good repeatability, this difference most likely reflects differences in the specimens themselves. This study shows clearly that the area of ligamentous attachment posterior to the auricular joint is large, covering some $22 \mathrm{~cm}^{2}$ (Table 2). We did not observe accessory SI joints in this posterior region (1), but one single joint had ankylosed there and was excluded from the present material. None of the other joints showed true intra- or periarticular ankylosis, although most showed areas of cartilage erosion and discoloration.

Large variations in responses occurred among the specimens, as demonstrated by the standard deviations and ranges (Tables 3 and 4). The stiffness of the test apparatus in any direction at these loads was two orders of magnitude larger than the joint stiffness measured. We checked for motion in the iliac mounting, which was relatively easy to see due to the translucent nature of the mounting acrylic cement, and found none. The center of the sacrum could only be estimated from external landmarks when mounting the specimen in the apparatus. Some of the small coupled motions could vary in direction due to variations in the line of action of the test forces. Inaccuracies in estimating the joint center position would have affected the calculated displacements linearly. The rotations would be unaffected as these were measured directly, with good repeatability, using the optical lever system. Our geometric study confirmed that errors in estimating the SI joint center were in fact random. On average, we estimated the center $(\mathrm{O})$ of the SI joint to within a millimeter of the actual center using external landmarks at the time of the specimen mounting. Thus, the data variations probably most likely reflect variations in the mechanical properties of the specimens.

The large load tests (Figs. 3 and 4) confirmed the linearity of the load-displacement curves over wide load ranges. Thus, stiffnesses reported at the loads used here probably accurately represent the stiffness at other load levels.

Our methods precluded measurement of all coupled motions, but they were adequate to capture the major motions of the sacrum under load. It should be noted that some of these motions could be modified in vivo by the presence of the other structures, such as the sacrospinous and sacrotuberous ligaments (29), which were purposely not included in these tests. The overall values for angular measurements made in the study of SI geometry may be compared with the results of earlier studies. The average value of SI joint inclination in the frontal plane was the same as that found by Solonen (30) in a study of 60 specimens. In the transverse plane, however, the agreement was not as good; on average, the present specimens had auricular surfaces aligned within $5^{\circ}$ of the sagittal plane and some $15^{\circ}$ less than values cited by Solonen. The data concerning the posterior ligamentous areas are new and thus cannot be compared with previous results.

To reduce the effect of the large interindividual differences in the inclination of the superior $\mathrm{S} 1$ endplate to the horizontal (known to range from $20^{\circ}$ to nearly $70^{\circ}$ ), the reference axes used in the present investigation were oriented with respect to the sacral endplate, and not the usual whole-body anatomic axes. It is a simple matter to transform these results through the average $40^{\circ}$ of sacral inclination in the sagittal plane to obtain the values in the more usual anatomical frame of reference.

It is instructive to compare single SI joint stiffnesses with those of lumbar spine motion segments regardless of their obvious differences in anatomy. In passing, one might note that the cross-sectional area of the single SI joint as defined in this paper is about $30 \%$ less than the cross-sectional area of an L3-4 intervertebral disc in a transverse plane section (14 and $20 \mathrm{~cm}^{2}$, respectively). We can express SI stiffness as a percentage of lumbar motion segment stiffness for a given test direction (Table 5). To simplify the comparison, test loads were applied normal or parallel to the vertebral endplates in both cases. Sacroiliac stiffnesses ranged from $5 \%$ for an inferiorly-directed test force (axial compression on a lumbar motion segment) to $624 \%$ for a mediallydirected force (lateral shear on a lumbar motion segment). In moment tests, SI stiffnesses ranged from $64 \%$ in axial torsion to $700 \%$ in lateral bending 
TABLE 5. Comparison of single sacroiliac (SI) joint stiffnesses with intact lumbar motion segments values

\begin{tabular}{|c|c|c|c|c|}
\hline \multirow[b]{2}{*}{ Direction } & \multirow{2}{*}{$\begin{array}{c}\text { SI Data } \\
\text { Stiffness }(\mathrm{N} / \mathrm{mm})\end{array}$} & \multicolumn{2}{|c|}{ Lumbar motion segments ${ }^{a}$} & \multirow{2}{*}{$\begin{array}{l}\text { Ratio: } \\
\text { SI/lumbar }\end{array}$} \\
\hline & & Nominal load & Stiffness $(\mathrm{N} / \mathrm{mm})$ & \\
\hline Superior & 157.2 & $450 \mathrm{~N}$ & $70^{b}$ & 2.24 \\
\hline Inferior & 297.0 & $400 \mathrm{~N}$ & $7843^{c}$ & 0.05 \\
\hline Anterior & 107.3 & $980 \mathrm{~N}$ & 166 & 0.65 \\
\hline Posterior & 187.9 & $980 \mathrm{~N}$ & 196 & 0.96 \\
\hline \multirow[t]{2}{*}{ Medial (lateral) } & 386.8 & $500 \mathrm{~N}$ & 62 & 6.24 \\
\hline & Stiffness $(\mathrm{N}-\mathrm{m} / \mathrm{deg})$ & & Stiffness $(\mathrm{N}-\mathrm{m} / \mathrm{deg})$ & \\
\hline Flexion & 15.7 & $70 \mathrm{~N}-\mathrm{m}$ & 5.4 & 2.91 \\
\hline Extension & 11.9 & $70 \mathrm{~N}-\mathrm{m}$ & 7.5 & 1.59 \\
\hline Lateral bending & 30.0 & $60 \mathrm{~N}-\mathrm{m}$ & 4.3 & 7.00 \\
\hline Torsion & 6.8 & $70 \mathrm{~N}-\mathrm{m}$ & 10.7 & 0.64 \\
\hline
\end{tabular}

Loads were applied parallel and normal to the superior S1 endplate in the case of the sacroiliac tests and the vertebral endplate in the lumbar segment tests. Sacroiliac nominal loads were $294 \mathrm{~N}$ and $42 \mathrm{~N}-\mathrm{m}$.

${ }^{a}$ Ref. $19 ;{ }^{b}$ Ref. $18 ;{ }^{c}$ Ref. 3.

compared with lumbar motion segments (Table 5). Thus, in some modes of loading, SI joints are much less stiff than lumbar motion segments, while in others they are much more stiff.

Acknowledgment: The support of Public Health Service grants AM 33948, NS 20536, and OH 01962, a grant from the Swedish Work Environment Fund, as well as the assistance of John Duff and Richard Romick-Allen, are gratefully acknowledged.

\section{REFERENCES}

1. Baklund $\mathrm{O}$, Hansen JH: The axial sacroiliac joint. Anat Clin 6:29-36, 1984

2. Bellamy N, Park W, Rooney PJ: What do we know about the sacroiliac joint? Sem Arth Rheum 12:282-313, 1983

3. Berkson MH, Nachemson A, Schultz AB: Mechanical properties of human lumbar spine motion segments-Part 11: Responses in compression and shear; influence of gross morphology. J Biomech Eng 101:53-57, 1979

4. Berner W, Rothkotter HJ, Hoyer H, Tscherne H: Biomechanische Untersuchungen am Ileosacralgelenk. In: Chirurgisches Forum ' 85 f. experim. u. klinische Forschung, ed by F. Stelzner, Berlin, Springer-Verlag, 1985, pp 1-4

5. Borlaza GS, Seigel R, Kuhns LR, Good AE, Rapp R, Martell W: Computed tomography in the evaluation of sacroiliac arthritis. Radiology 139:437-440, 1981

6. Bowen V, Cassidy JD: Macroscopic and microscopic anatomy of the sacroiliac joint from embryonic life until the eighth decade. Spine 6:620-628, 1978

7. Brooke R: The sacroiliac joint. J Anat 58B:299-305, 1924

8. Chamberlain WE: The X-ray examination of the sacroiliac joint. Delaware State Med J 4:195-201, 1932

9. Colachis S, Worden R, Bechtol C, Strohm B: Movement of the sacroiliac joint in the adult male: A preliminary report. Arch Phys Med 44:490-498, 1963

10. Cone RO, Resnick D: Roentgenographic evaluation of the sacroiliac joints. Orthop Rev 12:95-105, 1983

11. Dihlman W: Diagnostic Radiology of the Sacroiliac Joints New York, Thieme, 1980

12. Egund N, Olsson TH, Schmid H, Selvik G: Movements in the sacroiliac joints demonstrated with roentgen stereophotogrammetry. Acta Radiol Diag 19:833-846, 1978

13. Frigerio N, Stowe R, Howe J: Movement of the sacroiliac joint. Clin Orthop Rel Res 100:370-377, 1974

14. Goel VK, Svensson NL: Forces on the pelvis. $J$ Biomech 10:195-200, 1977

15. Grieve GP: The sacroiliac joint. Physiotherapy 62:384-400, 1976

16. Gunterberg B, Romanus B, Stener B: Pelvic strength after major amputation of the sacrum. An experimental study. Acta Orthop Scand 47:635-642, 1976

17. MacDonald GR, Hunt TE: Sacroiliac joints: Observations on the gross and histological changes in the various age groups. Can Med Assoc J 66:157-163, 1952

18. Markolf KL: Stiffness and damping characteristics of the thoracolumbar spine. Workshop on Bioengineering Approaches to Problems of the Spine, Washington D.C., NIH, 1970

19. Miller JAA, Schultz AB, Spencer DL, Warwick D: Mechanical properties of lumbar spine motion segments under large loads. J Biomech 19:79-84, 1986

20. Oonishi $\mathrm{H}$, Isha $H$, Hasegawa $T$ : Mechanical analysis of the human pelvis and its application to the artificial hip joint by means of the three dimensional finite element method. $J$ Biomech 16:427-444, 1983

21. Panjabi MM, Brand RA, White AA: Three dimensional flexibility and stiffness properties of the human thoracic spine. $J$ Biomech 9:185-192, 1976

22. Paquin ID, van der Rest M, Marie P, Mort JS, Pidoux I, Poole AR, Roughley PJ: Biochemical and morphologic studies of cartilage from the adult human sacroiliac joint. Arthritis Rheum 26:887-895, 1983

23. Resnick D, Niwayama G, Goergen TG: Comparison of radiographic abnormalities of the sacroiliac joint in degenerative disease and ankylosing spondylitis. AJR 128:189-196, 1977

24. Reynolds HM: Three dimensional kinematics in the pelvic girdle. J Am Osteopath Assoc 80:277-280, 1980

25. Roughley PJ, Curnew G, Mort JS, Poole AR, van der Rest $\mathrm{M}$ : Comparison of the organization and composition of collagen and proteoglycan in different regions of the human sacroiliac joint. Trans Orthop Res Soc 10:54, 1985

26. Sashin D: A critical analysis of the anatomy and pathological changes of the sacroiliac joints. $J$ Bone Joint Surg $12: 891-910,1930$ 
27. Schultz AB, Warwick D, Berkson M, Nachemson A: Mechanical properties of human lumbar spine motion segments. Part 1: Responses in flexion, extension, lateral bending and torsion. J Biomech Eng 101:46-52, 1979

28. Schunke AB: The anatomy and development of the sacroiliac joint in man. Anat Rec 72:313-331, 1938

29. Slocumb L, Terry RJ: Influence of the sacrotuberous and sacrospinous ligaments in limiting movements at the sacroiliac joint. JAMA 87:307-309, 1926

30. Solonen KA: The sacro-iliac joint examined in the light of anatomical, roentgenological and clinical studies. Acta Orthop Scand Suppl. 26:14-30, 1957

31. Vukicevic S, Plitz W, Vukicevic D, Vinter I, Bergmann M: Holographic study of the stresses in the human pelvis with particular relevance to the movement of the sacrum. In: Biomechanics: Principles and Applications: Developments in Biomechanics Vol. 1., ed by R Huiskes, DH van Campen, JR de Wijn, The Hague, Nijhoff Publ,, 1982, pp 233-240

32. Weisl $\mathrm{H}$ : Ligaments of the sacroiliac joint examined with particular reference to their function. Acta Anat 20:201213,1954

33. Weisl $\mathrm{H}$ : The articular surfaces of the sacroiliac joint and their relation to the movements of the sacrum. Acta Anat 22:1-14, 1954

34. Weisl H: The movements of the sacroiliac joint. Acta Anat 23:80-91, 1955

35. Whelan MA, Gold RP: Computed tomography of the sacrum. 1. Normal anatomy. AJR 139:1183-1190, 1982 